\title{
Effect of $70 \%$ alcohol swabbing and flushing technique on high speed contra angle toward bacterial count and identification of pathogens
}

\author{
Sri Mulyanti \\ Dental Health Department, Bandung Health Polytechnic, Ministry of Health Republic of Indonesia
}

\section{ABSTRACT}

High speed contra angle is a potential source of cross infection due to its working system in blowing up water, saliva and microorganisms from the patients, as well as dental unit water line contamination. This experimental Quasy laboratory study aimed to determine the reduce of bacteria in high speed contra angle after $70 \%$ alcohol swabbing and flushing for 30 seconds and identifying the presence of pathogen. This study was conducted on 35 lower molar teeth with caries without abscess in patients during pulp opening with the contra angle. Afterwards the contra angle was immersed in sterile aquadest and flushed. The immersed and flushed water were sampled then cultured on blood agar plates. The colony forming units were counted manually: Group I, was the control; Group II, after used on patients; and Group III, after treatment and swabbed with $70 \%$ alcohol and flushed. The data was statistically analyzed according to Anava and continued by test with least signifficant differences (LSD). The results showed that in bacterial identification there were pathogens. The bacteria amount was reduced after swabbing the contra angle from $50.88 \pm 40.33$ to $10.31 \pm 20.02$ cfus. After flushing the cfus decreased from $169.74 \pm 53.76$ to $73.03 \pm 36.39$. Based on the variant and LSD analyzes ( $p<0.01$ ), CFU were significantly different among the three groups. Conclusion: $70 \%$ alcohol swabbing and flushing could reduce bacterial amount in high speed contra angle and there were the presence of Staphylococcus aureus and Pseudomonas aeruginosa on the usage of high speed contra angle.

Key words: Swabbing, flushing, 70\% alcohol, high speed contra angle

\section{INTRODUCTION}

Most of dental instruments are potential infection source, because they always contact with oral mucosa, saliva, and blood. Furthermore, in certain conditions, contaminant microorganism can infect the dentist and dental nurse through these dental instruments. ${ }^{1}$

One of the instruments that is potential as infection source is the high-speed contra angle.
This instrument is used to drill the teeth before filling, to open the pulp chamber and also to drill the bone in certain dental surgery.

The high speed contra angle handpiece is a dental instrument that can cause cross infection, due to the working system of the instrument which include the ability to spray water for cooling effect and it will be mixed with saliva, blood and microorganism from patient oral cavity to contaminate the water line and air line located in 
the dental unit or dental unit water line (DUWL).

When it is turned off, the reverse suction mechanism is activated and this causes the saliva, dental debris, and blood from the oral cavity to be sucked/retracted to the instrument through the air line and will be detained inside it which eventually leads to bacterial accumulation that has a great potential for cross infection. ${ }^{3}$ If the instrument is used on the next patient then the materials from the previous patient be re-sprayed/resend to the patient's oral cavity. ${ }^{1,4,5}$

High speed contra angle that has been used since late 1950s noticeably contributes to the aerosol contamination containing bacteria in dental treatment. Microorganisms that are found in dental aerosol due to high-speed contra angle use are Staphylococcus spp, Streptococcus spp, Diphteroid, pneumococcus, Tubercle bacillus, Influenza virus, Hepatitis virus, Herpes virus hominis, and Neisseria spp. ${ }^{3}$ In addition to oral bacterial contamination, it is also contaminated by the water coming out from DUWL that contains bacteria. Based on a research performed in United States, bacteria that have been found in DUWL include Escherichia coli, Staphylococcus spp; Pseudomonas aeruginosa; Legionella spp; and Bacillus spp. ${ }^{6,7}$

Contra angle is not a single use instrument and it is very risky in terms of its role as the causal factor of cross infection in the dental clinic. It becomes harder to obtain a sufficient disinfection and hygiene level because the instrument has chamber and channels or lines that can hold infection material which is difficult to clean between patients. This instrument has disadvantages in the sterilization process because the inner components are very sensitive and may get damaged faster if it is several times in high temperature. Soaking in disinfectant liquid is not allowed because this can damage the inner components. $^{2,4}$

Based on a research performed by Hakimnia', the autoclave method is a sterilization method that is very effective and safe for contra angle. Samaranayakane ${ }^{8}$ suggested that the instrument should be sterilized using autoclave between patients. Meanwhile, based on the survey performed by American Dental Association (ADA), after using contra angle, most of the dentists rarely perform sterilization by using autoclave, because this instrument is expensive and the process is time-consuming, so it is not practiced routinely. As a result of this dilemma, the dentist usually only perform disinfection of the outer surface of contra angle.

In fact, based on the writer's observation, the dentists in Indonesia only perform disinfection by swabbing the outer surface of contra angle using cotton that has been wetted with $70 \%$ alcohol, while theinnercomponentsarenevercleaned, disinfected or sterilized, although the inner components are also contaminated with saliva, and blood.

American Dental Association (ADA) and Center for Disease Control (CDC) suggest flushing to clean the inner components of the instrument and remove dental debris, saliva or blood from the previous patient. Flushing technique should be performed for 20-30 seconds every time between patients. However, in reality the technique is not too familiar for most of the dentist and they even rarely or never perform it.

Based on the reasons above, the writer was interested to perform a study in order to find out the effect of alcohol swabbing that has been performed by most of the dentists by mixing it with flushing technique. This was aimed to reduce the bacterial number in the contra angle that had been used to open necrotic pulp chamber, and to identify the presence of pathogenic bacteria during the use of this instrument.

\section{MATERIALS AND METHODS}

The study samples were dental patients with pulp necrosis and cavum opening had been performed with a consideration that those teeth have been infected by bacteria compared to pulp hyperemia or pulpitis. In addition, cavum opening needs a long period, so it is likely that the contra angle was exposed by more bacteria.

The type of research was Quasi experimental and was performed in laboratory with research design of pre and post test designs based on the fact that the calculation of bacterial number was performed on high speed contra angle before and after being used by the patient and that had been treated with $70 \%$ alcohol swabbing and flushing technique for 30 seconds.

The preparation stage consisted of contra angle and basic dental instruments sterilization 
using autoclave, and then water tank in the dental unit is cleaned and filled by sterile aquadest. In $70 \%$ alcohol swabbing technique, the examination material is sterile aquadest that has been used to soak contra angle, while in the flushing technique, the material is the water that comes out from contra angle during flushing process.

Examination material sampling: (1) Contra angle that has been sterilized using autoclave and the sterile aquadest that has not been used by patient, the head was soaked in a test tube containing $25 \mathrm{ml}$ sterile aquadest for one minute while being shaken, then take the sample as control (A1); (2) Turn on the contra angle, water that comes out from contra angle spray that has not been used by the patient was kept in the test tube as much as $2 \mathrm{ml}$ as control (F1); (3) The patient was instructed to open his mouth and then performed pulp chamber opening using contra angle until the chamber opened; (4) The head of contra angle that had been directly used for the patient was soaked in the test tube with $25 \mathrm{ml}$ sterile aquadest for one minute while being shaken, then take the sample (A2); (5) After that, the contra angle was turned on again and the water that comes out form the syringe amounted $2 \mathrm{ml}$ was kept in the sterile test tube (F2); (6) Then the head of contra angle swabbed with cotton that had been wetted with alcohol, the head part soaked in the test tube of $25 \mathrm{ml}$ sterile aquadest for one minute, while being shaken and then take the sample (A3); (7) Performed flushing for 30 seconds, then the sample took as much as 2 $\mathrm{ml}$ and kept it in the sterile test tube (F3).

Examination in microbiology laboratory ${ }^{10}$ : For colony number calculation, take each material $(\mathrm{A} 1, \mathrm{~A} 2, \mathrm{~A} 3$, and $\mathrm{F} 1, \mathrm{~F} 2, \mathrm{~F} 3)$ using a loop that has been calibrated $(10 \mu \mathrm{L})$ to be cultured in blood agar plate using non-interrupted movement method, then incubate for 24 hours with $37^{\circ} \mathrm{C}$ temperature. On the following day, performed calculation of bacterial colony number for the colonies that grow in the blood agar plate. Towards different colonies, performed Gram staining to reveal the colony shape. Based on the microscopic examination result, an examination was performed to the colonies suspected as pathogenic bacteria for next identification. For instance, colony that was suspected as Staphylococcus and shows hemolysis test on BAP was followed up with coagulation test, if the result was positive, it was Staphylococcus aureus.

\section{RESULTS}

According to the result and calculation obtained from the blood agar plate which were taken from 35 samples, the results were as in Table 1. To determine whether there was any significant difference between A1, A2 and A3 groups, Anova statistical test was performed. The analysis result is shown in the Table 2.

According to $F$ test, the result was significantly different. To determine which group was different from $\mathrm{A} 1, \mathrm{~A} 2$, and $\mathrm{A} 3$ groups, the analysis was followed up by least significant difference method test (Tab. 3).

Different alphabets showed significant difference in 0.01 degree, this means that there was bacterial number difference in high speed contra angle before (A1), after used by the patient (A2) and after being treated (A3).

According to Table 1 , it can be concluded that there was an effect of $70 \%$ alcohol swabbing

Table 1. Bacteria average number in $70 \%$ alcohol swabbing technique.

\begin{tabular}{cccc}
\hline Group & A1 & A2 & A3 \\
\hline Average & $0.34 \pm 0.97$ & $50.88 \pm 40.33$ & $10.31 \pm 20.02$ \\
\hline
\end{tabular}

Table 2. Variance analysis on bacterial number using $70 \%$ alcohol swabbing technique.

\begin{tabular}{cccccc}
\hline Variation sources & DB & JK & RJK & $F_{\text {count }}$ & $F_{0.01}$ \\
\hline Patient (Replication) & 34 & 9.4744 & 0.2787 & & \\
Treatment & 2 & 41.3173 & 20.6586 & 211.883 & 4.9316 \\
Galat (Error) & 68 & 66320 & 0.0975 & $* *$ & \\
Total & 104 & 57.4236 & & & \\
\hline
\end{tabular}

Note: $\left.{ }^{* *}\right)$ Significant difference $\left(\mathrm{F}_{\text {count }}>\mathrm{F}_{0.01}\right)$. 
towards bacterial number on high speed contra angle that has been used, i.e. bacterial number decreases in contra angle that has been used by patient (A2), from 50.88 to 10.31 CFU after $70 \%$ alcohol swabbing (A3).

Effect of flushing technique towards bacterial number on high speed contra angle

According to result and bacterial number calculation on blood agar plate which was taken from 35 materials, it can be averaged as follow in Table 4. From the data, to find out whether there was any significant difference between F1, $F 2$, and F3 groups, Anova statistical test was then performed. The analysis results were shown in Table 5.

Table 3. Least significant difference method test on $70 \%$ alcohol swabbing.

\begin{tabular}{cccc}
\hline Replication & $\begin{array}{c}\text { Mean in log } \\
\text { transformation }\end{array}$ & Mean & $\begin{array}{c}\text { Significancy } \\
0.01\end{array}$ \\
\hline A1 & 0.0743 & 0.3429 & $\mathrm{a}$ \\
A2 & 1.5879 & 50.8857 & $\mathrm{~b}$ \\
A3 & 0.6020 & 10.3143 & $\mathrm{C}$ \\
\hline
\end{tabular}

Table 4. Bacterial colony number average in flushing technique.

\begin{tabular}{cccc}
\hline Group & F1 & F2 & F3 \\
\hline Average & $56.31 \pm 30.63$ & $169.74 \pm 53.76$ & $73.03 \pm 36.39$ \\
\hline
\end{tabular}

Table 5. Variance analysis of the bacterial number using flushing technique.

\begin{tabular}{cccc}
\hline Replication & $\begin{array}{c}\text { Mean in log } \\
\text { transformation }\end{array}$ & Mean & $\begin{array}{c}\text { Significancy } \\
\mathbf{0 . 0 1}\end{array}$ \\
\hline F1 & 1.6777 & 56.3143 & $\mathrm{a}$ \\
F2 & 2.2074 & 169.7429 & $\mathrm{~b}$ \\
F3 & 1.7876 & 73.0286 & $\mathrm{c}$ \\
\hline
\end{tabular}

Note: (F1) High speed contra angle that has not been used; (F2) High speed contra angle that has been used; (F3) High speed contra angle that has been flushed for 30 seconds.
According to the $F$ test, the result is significantly different. To determine which group that was different from F1, F2, and F3 groups, analysis was followed by least significant difference method test. The result is as follow.

Different alphabets show significant different in 0.01 degree, which means that there was bacterial number difference before being used by the patient and after being treated by flushing for 30 seconds.

It can be concluded that flushing technique affects the bacterial number in high speed contra angle, and there was bacterial number decrease in contra angle that has been used by the patient (F2), from 169.74 to 73.03 CFU, after flushing for 30 seconds (F3).

Bacterial identification result on contra angle that has been used for pulp chamber opening in necroses is explained in Table 7 and 8. Pathogenic bacterial type presentation found on contra angle outer surface that has been used to open necroses pulp chamber can be seen in Table 7. After flushing technique, bacterial type presentation found in the sprayed water from contra angle that had been used to open necrotic pulp chamber could be seen in the Table 8 . According to Table 7 and 8 ,

Table 7. Pathogenic bacterial presentation on $70 \%$ alcohol swabbing technique.

\begin{tabular}{cccc}
\hline \multirow{2}{*}{ No } & \multirow{2}{*}{ Bacteria type } & \multicolumn{2}{c}{ Percentage } \\
\cline { 3 - 4 } & & Before & After \\
\hline 1 & Staphylococcus aureus & $31.4 \%$ & $14.2 \%$ \\
\hline
\end{tabular}

Table 8. Pathogenic bacterial presentation on flushing technique.

\begin{tabular}{cccc}
\hline \multirow{2}{*}{ No } & \multirow{2}{*}{ Bacteria type } & \multicolumn{2}{c}{ Percentage } \\
\cline { 3 - 4 } & & Before & After \\
\hline 1 & Pseudomonas aeruginosa & $74.2 \%$ & $57.1 \%$ \\
2 & Staphylococcus aureus & $5.7 \%$ & $2.8 \%$ \\
\hline
\end{tabular}

Table 6. Least significant difference method test on flushing technique.

\begin{tabular}{cccccc}
\hline Variation sources & DB & JK & RJK & $F_{\text {count }}$ & $F_{0.01}$ \\
\hline Patient (Replication) & 34 & 4.9992 & 0.1470 & & \\
Treatment & 2 & 5.4708 & 2.7354 & $159.49^{* *}$ & 4.9316 \\
Galat (Error) & 68 & 1.1663 & 0.00172 & & \\
Total & 104 & 11.6363 & & & \\
\hline
\end{tabular}


the pathogenic bacteria in the contra angle that had been used to open necrotic pulp chamber were Staphylococcus aureus and Pseudomonas aeruginosa.

\section{DISCUSSION}

Based on the result of a study on the effect of $70 \%$ alcohol swabbing on contra angle that has been used to open necrotic pulp chamber showed that in the $\mathrm{A} 2$ group, the bacterial number was the highest, i.e. $50.88 \mathrm{CFU}$. This due to the fact that the contra angle has been contaminated by oral cavity bacteria. After being treated with $70 \%$ alcohol swabbing $(\mathrm{A} 3)$, the bacterial number decreased to $10.31 \mathrm{CFU}$.

The bacterial number decreased on the contra angle outer surface was caused by $70 \%$ alcohol activity as antimicrobial. Mahon ${ }^{11}$ proves that in $70 \%$ concentration, alcohol could kill vegetative form of bacteria, but the spore form was still alive. In addition, the mechanical effect of alcohol-cotton swabbing movement was also able to decrease the microorganism number in the instrument surface.

According to the result from the contra angle after being swabbed with $70 \%$ alcohol, there was still Bacillus spp exists. This bacterium was a spore bacterium and it survives because $70 \%$ alcohol couldnot kill spore. The weakness of $70 \%$ alcohol includes the fact that it can easily evaporate from the surface being disinfected; this limits the alcohol activity towards the bacteria. The $70 \%$ alcohol effectiveness is very much influenced by protein, such is found in the saliva and blood. ${ }^{11}$

Therefore, the instrument surface that will be disinfected by $70 \%$ alcohol should be cleaned first from debris, saliva, and blood that adhere to the surface, so that the $70 \%$ alcohol can directly contact the surface.

So, swabbing using cotton wetted by $70 \%$ alcohol is not dependable to sterilize the instruments, but it is only used to reduce the bacterial number. ${ }^{3,8}$

Based on the results and statistical test performed to see the effects of contra angle flushing technique to open with, it was shown that there were colony number differences between $F 1, F 2$ and F3.

In control group (F1), even though the contra angle had been sterilized by autoclave and the water that was used as cooler was sterile aquades, there was still a small amount of bacteria presence in the water that comes out from the instrument. This was due to the fact that a biofilm has been formed in the water irrigation system in dental unit (DUWL) that flows through the instrument. The release of bacteria from biofilm in the pipe wall can increase the bacterial population that is already in the water, and it is possible that pathogenic bacteria are also found among them. ${ }^{1,7}$

In F2 group, the bacterial number increased to $169.45 \mathrm{CFU}$. This was resulted from the increased number of bacteria from oral cavity that were sucked by the instrument and enter the DUWL, so the water that was sprayed during the use of the instrument was contaminated by oral cavity and biofilm bacteria.

In F3 group, the bacterial number decreased to $73.03 \mathrm{CFU}$. This was resulted from the flushing process, i.e. rinsing in the water irrigation of the instrument and DUWL to clean the inner parts of infection materials. This approach was supported by the Center for Disease Control Guidance that suggests to perform flushing for 20-30 seconds between patients in order to eliminate and reduce the microorganism and dental debris found in the water irrigation that come from biofilm and previous patient. $^{3}$

Biofilm formation is supported by many factors, the water residue retained inside the pipe while the dental unit is not used is one of the causal factors of the formation. Microorganism enters the pipe continuously and results in bacterial accumulation in the pipe. Biofilm can also be formed due to re-suction force from the instruments such as high speed angle that can carry the bacteria from the patient mouth to DUWL during oral and dental treatment. ${ }^{7}$

Many dentists have wrong perception; they believe that the use of water that has been cleaned or sterilized in dental unit can reduce the problem. It is important to remember that it is possible that the biofilm colony is already formed in the pipe, so the cleaned and sterilized water could be contaminated while flowing through the pipe. Therefore, it is proven that flushing process for 30 seconds can decrease the bacterial number, from 169.45 to $73.03 \mathrm{CFU}$. 
Based on Table 7, the percentage of pathogenic bacterial type found showed $31.4 \%$ of Staphylococcus aureus before $70 \%$ alcohol swabbing was performed. After the swabbing for 1 minute on the outer surface of the contra angle, a reduction in bacterial number to $14.2 \%$ was seen. The reduction was caused by the activity of $70 \%$ alcohol as disinfectant that can kill the vegetative form of bacteria as well as the mechanical effect of the swabbing movement that may clean or remove the bacteria.

The habitat of this bacterium is on human skin and mucosal membrane especially the anterior nares. It is rarely found in oral cavity and if it is found in oral cavity, it will be only as temporary bacteria especially in a suppurative infection. This bacterium can be disseminated through the air and dust and it is a main cause of nosocomial infection, especially for antibiotic resistant bacteria. ${ }^{8}$

The presence of this bacterium on the outer surface of the contra angle may be assumed as contamination from the air in the dental clinic that has been contaminated by the bacterium because Staphylococcus aureus is a bacterium that can survive in the air. During the dental pulp chamber opening using contra angle, the instrument may touch the patient's skin around the mouth and nose which may have Staphylococcus aureus. In addition, the contamination may be due to the operator himself who brings the bacteria on his hand.

Staphylococcus aureus can trigger infection of the root canal, jaw osteomyelitis, and dentoalveolar abscess. ${ }^{8,12}$ This bacterium is a causal agent of nosocomial infection with around $20 \%$ of bacterial infection is caused by this bacterium, only beaten by $E$. coli and Pseudomonas aeruginosa. Other non pathogenic bacteria found are the normal oral cavity flora. The most dominant is a-Streptococcus that is always found in every examination material. This is due to the fact that a-Streptococcus is the mouth normal flora and its number is the highest compared to other bacteria. The most frequently found a-Streptococcus is Streptococcus viridans that usually lives in oropharynx.

Based on the study, less than $90 \%$ of a Streptococcus could be isolated from plaque. ${ }^{13}$ Streptococcus viridans was non pathogenic, except if the bacteria move to another place.
Other bacterium found in addition to $a$ Streptococcus was Neisseria spp. that can be isolated on the tongue, saliva, oral mucosa and new plaque. The characteristics of this bacterium was aerob or facultative, positive oxidase, nonpathogenic and negative Gram coccus. The main species was Neisseria subflava, Neisseria sicca and Neisseria mucosa. ${ }^{13,8}$

In small amount, Diphteroid, Lactobacillus spp, Haemophylus spp and micrococcus are normal flora in the oral cavity. These bacterial are normal oral flora that is taken and adhere to when the instrument is used in the oral cavity.

Based on Table 8 it could be seen that the pathogenic bacterial type percentage found before flushing was Pseudomonas aeruginosa (74.2\%), and Staphylococcus aureus (5.7\%). After flushing for 30 seconds, there was a decline in bacterial number, i.e. Pseudomonas aeruginosa of $57.1 \%$ and Staphylococcus aureus of $2.8 \%$. This happens due to the flushing process for 30 seconds that can rinse and clean the water irrigation in the dental unit so some of the bacteria will be flushed during the flushing.

Pseudomonas aeruginosa in high contra angle is not originated from patient's oral cavity, but from water that flows in the instrument. This bacteria can colonize to form biofilm in the water irrigation in the dental unit and will be released to contaminate the water and then taken along through the instrument.

It is proven that based on a research in United State that the contaminant bacteria are found in DUWL including Escherichia coli, Staphylococcus spp., Pseudomonas aeruginosa, Legionella spp., and Bacillus spp. ${ }^{6,7}$

Pseudomonas aeruginosa is an opportunistic pathogenic bacterium that can survive in water (water container and water irrigation) and create biofilm for a long time. ${ }^{14}$ This bacterial is dangerous because of its antibiotic resistant nature (multiresistance). This is why Pseudomonas aeruginosa is considered as a dangerous and lethal pathogen, especially because it can trigger nosocomial infection. According to CDC, all Pseudomonas aeruginosa infections in hospitals in United State reach an average of $0.4 \%$ ( 4 of 1000 patients released from hospital), and the bacteria is the fourth of most isolated nosocomial pathogen types. ${ }^{14}$

Pseudomonas aeruginosa is an opportunistic 
pathogenic bacteria that results in infection in patient with poor immunity, such as patients with burns and cancer. Other diseases caused by this bacterium are endocarditis, osteomyelitis and foliculitis. ${ }^{1,14}$

Staphylococcus aureus is found in the water that goes through the instrument (DUWL) due to re-suction force of instruments like high speed contra angle that can carry the bacteria from the patient mouth to DUWL during oral and dental treatment. Others non-pathogenic bacteria are found such as a-Streptococcus, Neisseria spp., Diphteroid, Lactobacillus spp., and Haemophylus spp. that are carried or sucked to DUWL during oral and dental treatment. ${ }^{8}$

Based on the results of the study, although both techniques were applied, i.e. $70 \%$ alcohol swabbing and 30 second flushing, pathogenic bacteria such as Staphylococcus aureus and Pseudomonas aeruginosa were still found. Therefore, to eliminate the risk of cross infection at the dental clinic, the dental operators should work aseptically in every action, including sterilization of dental instruments that have been used for every patient and wear personal protection equipment such as mask, gloves and protection clothes.

\section{CONCLUSION}

Seventy percent alcohol swabbing on highspeed contra angle that had been used on a patient to open the necrotic cavity was able to decrease the bacterial number. The flushing technique for 30 seconds that was performed on high speed contra angle between patients was able to decrease the bacterial number. Although both technique have been performed, there are still Staphylococcus aureus and Pseudomonas aeruginosa found in the high-speed contra angle.

\section{REFERENCES}

1. Miller $\mathrm{CH}$, Palenik CJ. Infection control and management of hazardous materials for the dental team. St. Louis: Mosby Co.; 1998. p. 78,82-4,132-4,145-52,166-7,192.

2. Lewis DL, Boe RK. Cross-infection risks associated with current procedures for using high-speed dental handpiece. J Clin Microbiol 1992;Feb:401-6.

3. Cottonee JA, Terezhalmy GT, Molinari JA. Practical infection control in dentistry. Philadelphia: Lea \& Febiger; 1991. p. 3,1445,165 .

4. Recommended infection control practices for dentistry. Atlanta Georgia: Department of Health and Human Service CDC. 1993. p. 13-4.

5. Oeding $M$. Infection control. Bloomington: Foundations in Continuing Education; 2004. p. 30-4.

6. Bednard HS, Eklund KJ, Mills S. Check your dental unit water IQ. J Am Dent Hygien Assoc 1997;10(9):1-11.

7. Barbeau J. Waterborne biofilms and dentistry: the changing face of infection control. J Can Dent Ass 2000;66:539-41.

8. Samaranayake LP. Essential microbiology for dentistry. Edinburg: Churchil Livingstone; 2002. p. 207-39, 255-8.

9. Hakimnia E. Effectivenes of autoclaving for sterilization of high-speed turbines and handpiece. Stockholm Sweden: Department of Oral Diagnostics Faculty of Odontology Karolinska Institute; 1998.

10. Cappuccino JG, Sherman N. Microbiology a laboratory manual. Addison Wesley Publishing Co.; 1993. p. 31-6,81-3.

11. Mahon CR, Manuselis $G$. Text book of diagnostic microbiology. Philadelphia: W.B. Saunders Co.; 2000. p. 332,335-6,422.

12. Schuster GS. Oral microbiology \& infectious disease. Philadelphia: B.C. Decker Inc.; 1990. p. 166, 203-8,

13. Mc Ghee JR, Michalek SM, Cassel GH. Dental microbiology. Philadelphia: Harper \& Row Publisher; 1982. p. 204-7,654-60.

14. Todar K. The bacterial flora of human. Normal flora of human oral cavity. Winconsin: Department of Bacteriology University of Wisconsin; 2002.

15. Todar K. Pseudomonas aeruginosa. Winconsin: Department of Bacteriology University of Wisconsin; 2002.

16. Shearer BG. Biofilm and the dental office. J Dent Assoc 1996;127:181-9. 